\title{
Fault model of the 2007 Noto Hanto earthquake estimated from PALSAR radar interferometry and GPS data
}

\author{
Yo Fukushima $^{1}$, Taku Ozawa ${ }^{2}$, and Manabu Hashimoto ${ }^{1}$ \\ ${ }^{1}$ Disaster Prevention Research Institute, Kyoto University \\ ${ }^{2}$ National Research Institute for Earth Science and Disaster Prevention
}

(Received June 29, 2007; Revised November 18, 2007; Accepted November 22, 2007; Online published February 19, 2008)

\begin{abstract}
The 2007 Noto Hanto earthquake $\left(M_{\mathrm{w}} 6.6\right)$ is the first major earthquake in inland Japan since the launch of the Japanese ALOS satellite. Interferometric synthetic aperture radar successfully mapped the coseismic displacements from both ascending and descending orbits in and around the earthquake epicentral region. The line-of-sight displacements toward the satellite from the ascending and descending orbits amount to about 50 and $20 \mathrm{~cm}$, respectively. The interferograms as well as the GPS data of the GEONET network are inverted in order to determine the slip distribution on the source fault. The dip and strike angles of the preferred model are $48^{\circ}$ and $\mathrm{N} 51^{\circ} \mathrm{E}$, respectively, and its fault slip area reaches the seafloor. The dip angle is not well constrained in our tested range between $40^{\circ}$ and $60^{\circ}$. The dominant slip area is located just above the hypocenter, at depths between 4 and $10 \mathrm{~km}$. Many aftershocks seem to have occurred on and around the area of dominant slip.
\end{abstract}

Key words: Slip distribution, Noto Hanto earthquake, ALOS, PALSAR, SAR interferometry, GEONET, GPS.

\section{Introduction}

A $M_{\mathrm{w}} 6.6\left(M_{\mathrm{j}} 6.9\right)$ earthquake occurred on 25 March 2007 approximately $10 \mathrm{~km}$ beneath the western coast of the Noto Peninsula (Fig. 1). This earthquake shook the city of Wajima and surrounding areas, resulting in one death and more than 300 wounded. This earthquake marks the largest historical earthquake in and off the Noto Peninsula. In 1993, a $M_{\mathrm{j}} 6.6$ earthquake occurred $70 \mathrm{~km}$ northeast of this earthquake (Fig. 1; Ito et al., 1994; Tsukuda et al., 1994). More broadly, some large earthquakes equal to or larger than the 2007 Noto Hanto earthquake have occurred around the northwestern coast of central and western Japan (eastern margin of Japan Sea) in the last several years $\left(M_{\mathrm{w}} 6.8\right.$ Western Tottori in 2000; $M_{\mathrm{w}} 6.5$ Mid Niigata Prefecture in 2004; $M_{\mathrm{w}}$ 6.6 West Off Fukuoka Prefecture in 2005).

As the earthquake occurred in a shallow crust, it caused ground surface displacements observable by geodetic techniques. The GPS network GEONET operated by the Geographical Survey Institute (GSI) recorded up to $21 \mathrm{~cm}$ of coseismic horizontal displacements (Geographical Survey Institute, 2007). The Japan Aerospace Exploration Agency (JAXA) employed emergency observations of PALSAR, a synthetic aperture radar (SAR) onboard the Advanced Land Observing Satellite (ALOS). The ALOS satellite, launched on 26 January 2006, is a successor of the JERS-1 satellite operated in 1992-1998. PALSAR shares a number of characteristics with its predecessor, notably the waveband (Lband; wavelength $23.6 \mathrm{~cm}$ ). The L-band has been shown to have a great advantage over the $\mathrm{C}$-band for detecting ground displacement signals on vegetated areas (e.g., Rosen et al.,

Copyright (c) The Society of Geomagnetism and Earth, Planetary and Space Sciences (SGEPSS); The Seismological Society of Japan; The Volcanological Society of Japan; The Geodetic Society of Japan; The Japanese Society for Planetary Sciences; TERRAPUB.
1996). This earthquake marks the first major earthquake in inland Japan since the launch of the ALOS satellite.

This study proposes a fault model of the earthquake by inverting the interferometric SAR (InSAR) data and the GEONET GPS data. Section 2 explains the PALSAR data and the interferometric processing. The following sections describe the data set used for the inversions, provide estimations of the fault plane and its slip distribution, and discuss the results in relation with the aftershock hypocenter locations.

\section{PALSAR Interferograms}

At the moment of writing, two pairs of PALSAR images are available to compute coseismic SAR interferograms (Table 1). The first pair consists of images acquired on 23 February and 10 April 2007, observed from an ascending orbit with the off-nadir angle $41.5^{\circ}$. The second pair consists of images acquired on 23 December 2006 and 10 May 2007 , observed from a descending orbit with the off-nadir angle $34.3^{\circ}$. The processing was done using GAMMA software. To eliminate the effect of the difference in the satellite positions for the two acquisitions of a pair, 50-m mesh digital elevation models provided by the GSI were used. Single-look complex images were generated from concatenated raw data of two scenes. Fringes that result from any inaccuracies in the orbit data (e.g., Hanssen, 2001) were suppressed by tuning the satellite position of the second, i.e., more recently acquired, image.

The ground surface targeted by the radar is dominated by forest and includes some urban areas (buildings and roads) and cultivated areas (Fig. 1). The computed interferograms (Fig. 2) show good coherency, even in forest areas, which allows the ground surface line-of-sight (LOS) displacements in the whole observation area to be perfectly 
Table 1. Interferograms processed for this study.

\begin{tabular}{cccccc}
\hline Sensor & Orbit $^{\mathrm{a}}$ & $\begin{array}{c}\text { Period } \\
(\mathrm{DD} . \mathrm{MM} . Y Y)\end{array}$ & $\begin{array}{c}\text { Incidence } \\
\text { Angle }\left(^{\circ}\right)\end{array}$ & $\begin{array}{c}\text { Cross-track } \\
\text { Angle }\left(^{\circ}\right)\end{array}$ & $\begin{array}{c}\text { Perpendicular } \\
\text { baseline }(\mathrm{m})\end{array}$ \\
\hline PALSAR & $\mathrm{A}$ & $23.02 .07-10.04 .07$ & 47 & N80E & 238 \\
PALSAR & $\mathrm{D}$ & $23.12 .06-10.05 .07$ & 39 & N80W & 442 \\
ASAR $^{\mathrm{b}}$ & $\mathrm{D}$ & $24.12 .06-08.04 .07$ & 23 & N78W & -813 \\
ASAR $^{\mathrm{b}}$ & $\mathrm{D}$ & $03.03 .06-27.04 .07$ & 23 & N78W & -840 \\
\hline
\end{tabular}

${ }^{\mathrm{a}} \mathrm{A}$ : ascending, D: descending. ${ }^{\mathrm{b}}$ Unused by the inversions.

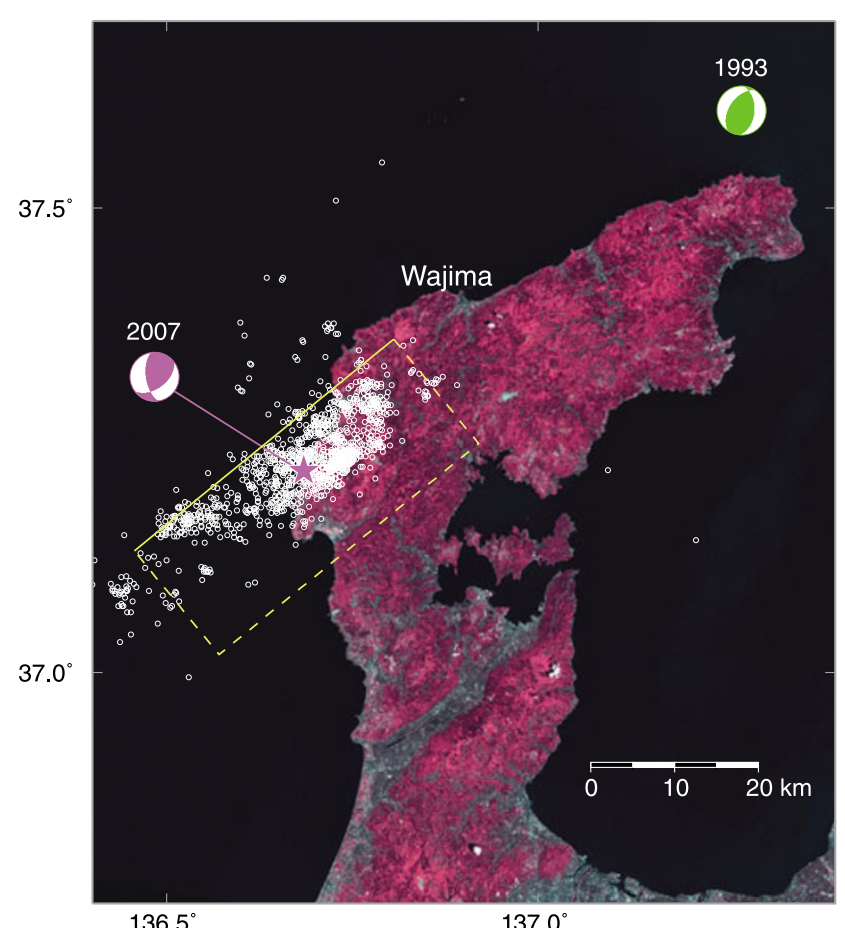

Fig. 1. Landsat ETM+ false-color image (Red: 4, Green: 3, Blue: 2) in Noto Peninsula (NASA Landsat Program, 2004). Red and gray colors roughly correspond to forest and urban regions, respectively. Mechanism and location of the mainshock is shown in magenda and was taken from the Japanese Meteorological Agency Centroid Moment Tensor catalogue. White circles indicate the epicenters of the aftershocks. Mechanism and location of the 1993 event is shown in green. Yellow box indicates the fault location estimated in this study, where the solid line is the top margin.

mapped. These high quality interferograms are in contrast to those computed using the European ASAR data (Cband) onboard the ENVISAT satellite, on which we failed to obtain any meaningful signals due to severe decorrelation (Table 1). The PALSAR interferograms (Fig. 2) therefore demonstrate the advantage of L-band PALSAR data in densely vegetated area.

The ascending interferogram (Fig. 2(a)) indicates up to about $50 \mathrm{~cm}$ of range decrease, with its maximum located close to the epicenter. Here, range means the distance between the radar antenna and ground. Range decrease and increase correspond to a LOS ground displacement toward and away from the satellite, respectively. The descending interferogram (Fig. 2(b)) shows, in turn, less fringes corresponding to a maximum range decrease of about $20 \mathrm{~cm}$ close to the epicenter and a maximum range increase of about $10 \mathrm{~cm}$ to the east.
Some ground cracks have been identified after the earthquake occurrence, including a $8-\mathrm{cm}$ right-laterally dislocated crack across a road (Ishiwatari et al., 2007). The two interferograms show no discontinuity associated with a surface fault movement, indicating that the fault does not reach the ground surface at least on the onshore area.

\section{Inversion}

\subsection{Data set}

We simultaneously invert the ground displacements obtained from InSAR and GEONET GPS data (F2 solution processed by the GSI) using the analytical expression of Okada (1985), which calculates the ground displacements caused by a rectangular dislocation in a homogeneous, isotropic and linearly-elastic half space. A GPS survey following the earthquake occurence shows that the maximum postseismic displacement in the first one and a half month is about a few centimeters (Hashimoto et al., 2008), which is one order less than the coseismic signal. We therefore neglect the postseismic deformation and assume that all of the displacements observed by InSAR were caused by coseismic fault slips. Since the InSAR and GPS data contain an unknown offset, displacements far from the epicenter are assumed to be zero.

For the tractability of the problem, we subsampled the two interferograms beforehand using a quadtree partitioning (Samet and Webber, 1988). The numbers of data points were reduced to 188 for the ascending and 133 for the descending interferograms (Fig. 3). These data points as well as three components of 45 GPS stations surrounding the earthquake epicentral region are used in the inversion. The weight of the data are set to be the squared inverse of the standard deviations, assumed as $20 \mathrm{~mm}$ for InSAR, $5 \mathrm{~mm}$ for the GPS horizontal components, and $10 \mathrm{~mm}$ for the GPS vertical component. Tilting of some GPS stations close to the earthquake fault (Togi and Notojima) has been reported by the GSI, and thus the data of these stations are not used.

\subsection{Determination of the fault plane}

We first determine the geometry of the fault, i.e., its location, dip, and strike angles. As the first step, we give an initial estimation of the fault plane from the aftershock hypocenter distribution. We assume that the aftershocks are symmetrically distributed with respect to the fault plane, and we determine the plane in such a way that the sum of the squared distance of hypocenters from the plane becomes minimum. We use the hypocenters of the aftershocks, published in a preliminary event catalog of the Japan Meteorological Agency, that occurred approximately in 1 month after the mainshock occurence. A plane in a 


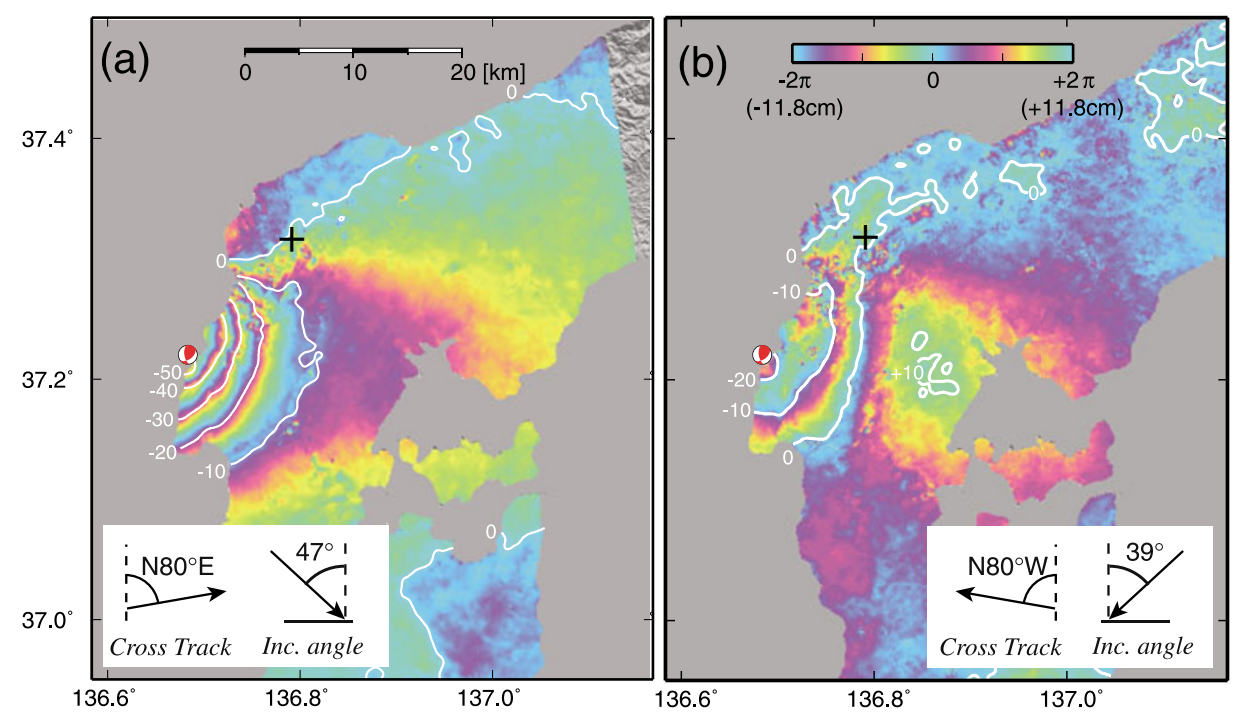

Fig. 2. SAR interferograms computed from PALSAR data. (a) Ascending data, (b) descending data. The displacement contours (white curves) are drawn from unwrapped interferograms with an assumption that the displacements far from the epicenter are zero. One color cycle of blue-green-yellow-purple corresponds to a LOS displacement of $11.8 \mathrm{~cm}$ toward the satellite. The location and the mechanism of the mainshock are also shown. Plus signs denote the location of a $8-\mathrm{cm}$ ground crack identified on a road.
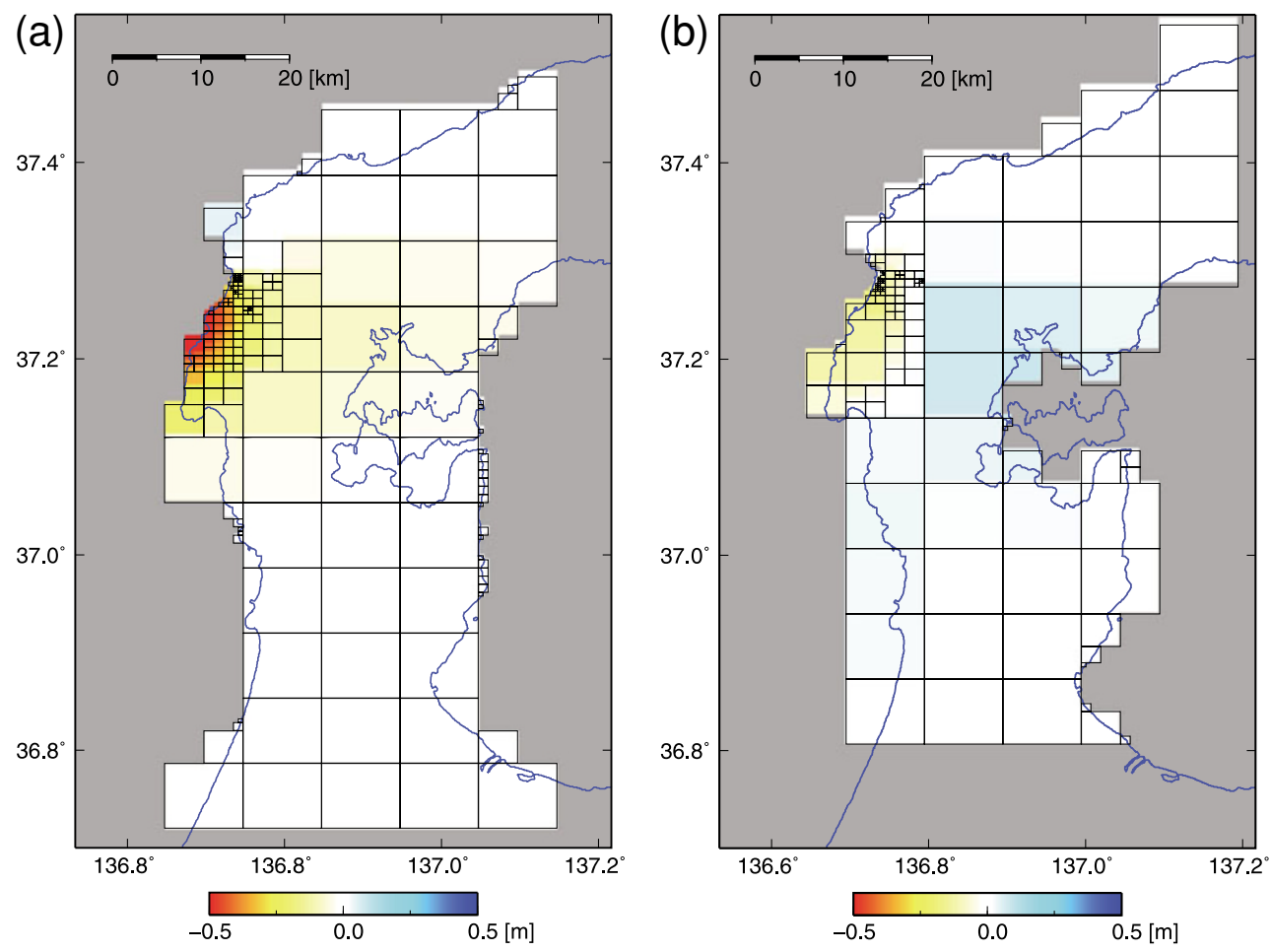

Fig. 3. Quadtree partitioning for ascending (a) and descending (b) interferograms, respectively. The centers of each quadrants are used as data points in the inversion. Three-component GPS data at 45 GEONET stations are also used (see Fig. 5(e, f)).

Table 2. Optimum fault parameters for a uniform slip model.

\begin{tabular}{cccccc}
\hline Latitude $^{\mathrm{a}}$ & Longitude $^{\mathrm{a}}$ & Depth (top margin) & Dip angle & Strike slip $^{\mathrm{b}}$ & Dip slip \\
\hline $37.204^{\circ}$ & $136.571^{\circ}$ & $200 \mathrm{~m}$ & $43^{\circ}$ & $0.31 \mathrm{~m}$ & $1.27 \mathrm{~m}$ \\
\hline
\end{tabular}

${ }^{\mathrm{a}}$ Upper-west corner. ${ }^{\mathrm{b}}$ Right-lateral component.

three-dimensional space is described by three parameters. Neighbourhood Algorithm (Sambridge, 1999). The latitude Here we take the longitude of a point on the plane, dip angle, and strike angle as the three parameters and estiand altitude of the point on the plane are fixed to $37.191^{\circ}$ mate their values from the hypocenter distribution using the and $0 \mathrm{~km}$, respectively. The obtained optimum plane includes a point (latitude, longitude, altitude $=37.191^{\circ}$, 
$136.52^{\circ}, 0 \mathrm{~km}$, respectively) and has dip and strike angles of $53.5^{\circ}$ and $\mathrm{N} 50.7^{\circ} \mathrm{E}$, respectively.

The hypocenter locations used above depend on the velocity model used, and hence inherently contain random and systematic errors. Systematic errors in particular lead to erroneous estimation of the fault plane, whereas the effect of random errors is averaged out. Since the systematic error in the depth is much larger than that in the horizontal location, the estimation of the longitude of a point on the plane and the dip angle are relatively unreliable compared to that of the strike angle. For this reason, we next fixed the strike angle to $\mathrm{N} 50.7^{\circ} \mathrm{E}$ and performed grid-searching in order to determine the other fault parameters. This corresponds to inverting for a rectangular uniform slip model with its strike angle fixed. The grid-searched parameters and the optimum values are listed in Table 2 . The plane shifted from the initial location by $2.3 \mathrm{~km}$ to the southeast at the ground surface level.

In the context that the fault plane parameters should ideally be estimated simultaneously with the slip distribution, these obtained fault parameters are still not optimum. The location of the upper extension of the fault, however, should roughly coincide with the border of range increase and range decrease regions in the interferograms and can be considered to be well constrained. The remaining geometrical parameters of the fault, i.e., the dip angle and the depth of the top margin, are re-estimated in the next subsection simultaneously with the fault slip distribution.

\subsection{Fault slip distribution}

For a specific fault geometry, we enlarge the fault along the plane, divide it into patches, and estimate the slip distribution by permitting different amounts and directions of plane-parallel dislocations on the patches. Each patch is set to be $2 \times 2 \mathrm{~km}$. We assume a $40 \times 24 \mathrm{~km}$ fault by placing 20 patches along strike and 12 patches along dip directions, and estimate the fault-slip vector in each patch. In this estimation, we use the smoothness constraint (Menke, 1989) to stabilize the solution, and its strength is determined so that Akaike's Bayesian Information Criterion (Akaike, 1980) is minimized. Further, slips are forced to be zero at the eastern, western, and lower margins.

We first perform slip inversions for different dip angles for the entire fault. Here the uppermost patches are assumed to reach the ground. The horizontal location and strike angle of the fault plane are fixed to the value obtained in the previous subsection (Table 2). Figure 4(a) shows the RMS residuals for the tested dip angles, each of which are computed after a slip inversion. The optimum value is $48^{\circ}$, which we take as our preferred value. The variation of the RMS residuals is small compared with the observation uncertainty, suggesting that the dip angle cannot be well constrained from the used data set. Next, we fix the dip angle to $48^{\circ}$ and test different depths of the top margin of the uppermost patches. Based on the residual (Fig. 4(b)), we take the upper limit of the fault patches to be $0 \mathrm{~km}$ as our preferred value. With this geometry, the slip area is permitted to reach the ground. This model does not contradict with the fact that no ground surface fault is observed in land area, because significant slips at the shallowest patches are predicted in the sea area. Our result implies that the fault may
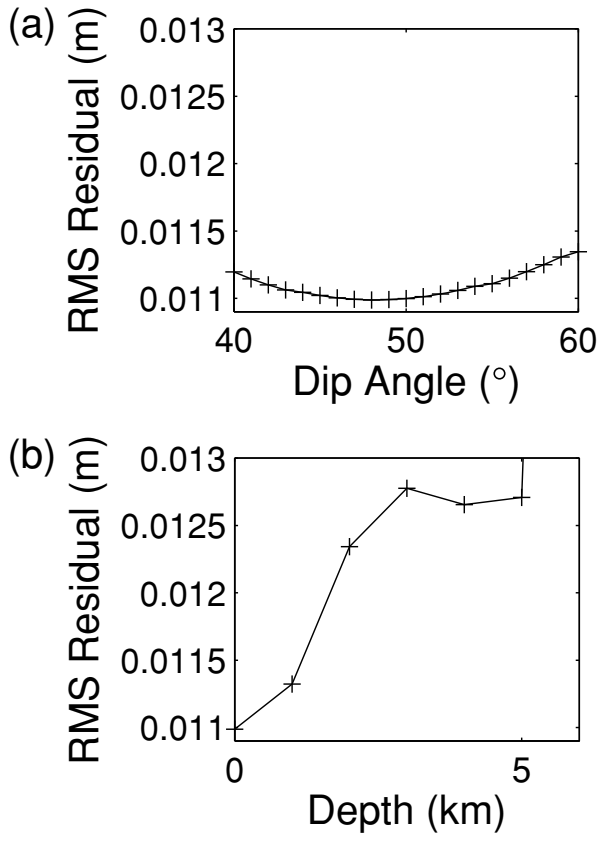

Fig. 4. (a) RMS residuals for different fault dip angles. The top margin of the fault is assumed to reach the ground. (b) RMS residuals for different depths of the top margin of the fault. The dip angle is assumed to be $48^{\circ}$.

indeed be reaching the seafloor, although it is possible that the upper limit of the slip area is located a few hundred meters beneath the seafloor considering the resolution limit of our problem.

The modeled data computed from our preferred model and the residuals are shown in Fig. 5(a-d). The general pattern of the observed interferometric fringes is explained. Relatively large residuals are observed close to and north of the fault top margin (Fig. 5(b)) and in a broader area above the entire fault (Fig. 5(b, d)). The former is a direct consequence of an unrealistic slip on the uppermost patches beneath this area that results from the lack of data points in the corresponding area (see Fig. 3) and from the assumption of the smoothness in the slip distribution. As will be shown below, however, the amount of fault slip of this part is less than $10 \mathrm{~cm}$, and hence this residual does not have any essential effect on our conclusion. The latter, the residuals in a broader area, probably result from a combination of imperfectness in our inversion and atmospheric noise. A future work is needed for the reduction of these residuals. A suggestion of improvement includes re-subsampling the interferogram data points in such a way that more points are put in the areas having large residuals. Comparison of the observed and modeled GPS data (Fig. 5(e, f)) indicates that the data showing relatively large displacements (more than about two centimeters) are fairly well explained, but that smaller displacements are not necessarily well explained. This perhaps indicates that some GPS stations are affected by local movement.

The main slip on the fault is estimated to have occurred in an area just above the hypocenter, at depths between 4 and $10 \mathrm{~km}$ (Fig. 6(a)). This slip area extends in an upperwest direction to the ground surface. The shallower slip area lies beneath the sea and has a limited resolution; how- 
(a) Modeled (Ascending)

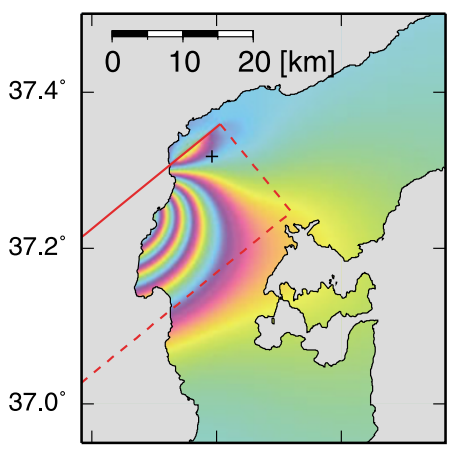

(b) Residual (Ascending)

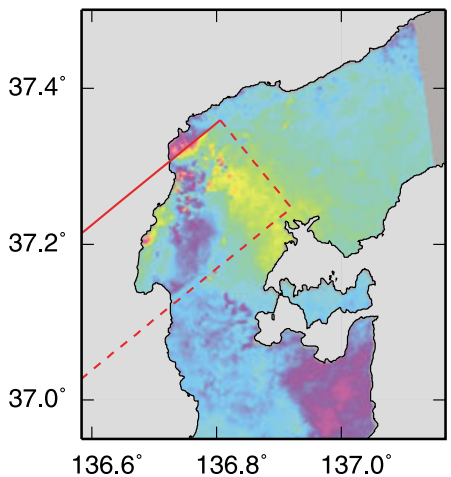

(c) Modeled (Descending)

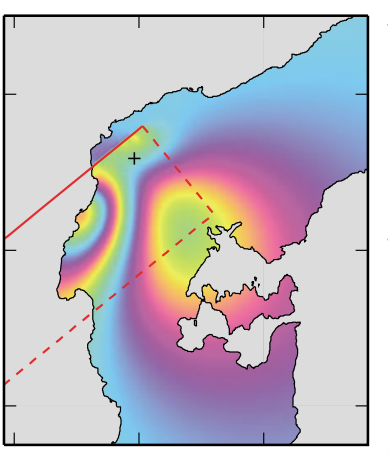

(d) Residual (Descending)

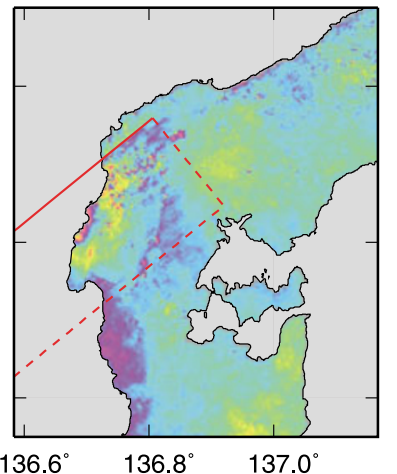

(e) GPS horizontal

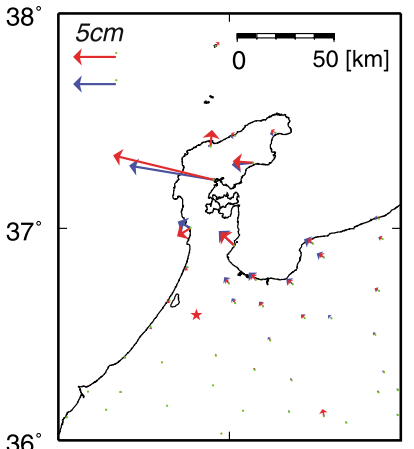

(f) GPS vertical

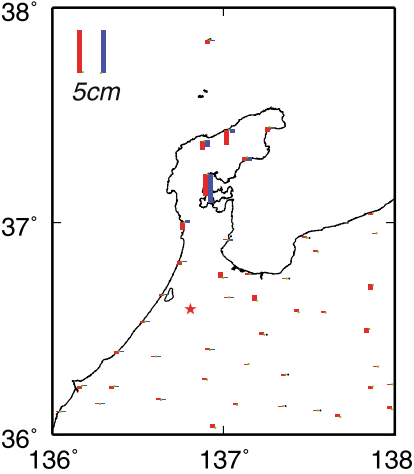

Fig. 5. (a) and (c) Ascending and descending interferograms predicted from our preferred model. Red lines show the location of the fault plane on which slips were permitted. (b) and (d) Residual interferograms computed from subtraction of the observed interferograms (Fig. 2) from (a) and (c). (e) and (f) Comparison of the observed and modeled GPS data for horizontal and vertical components. Red $=$ observation, Blue $=$ model. Red stars indicate the reference point where displacements are assumed to be zero.

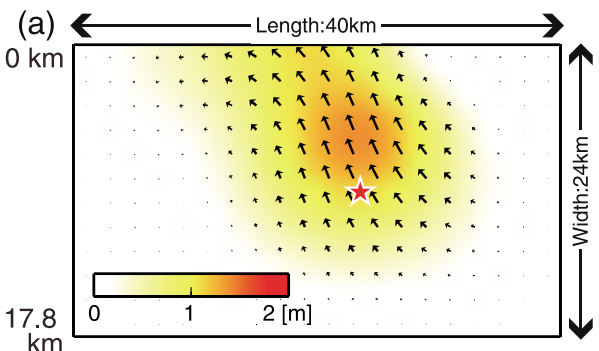

(b)

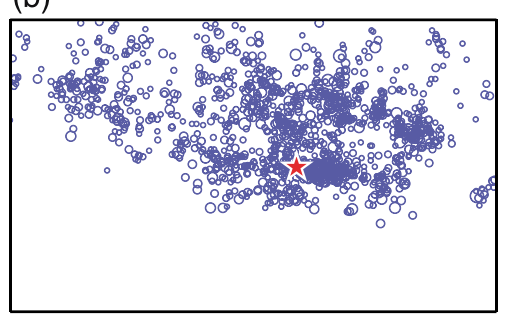

(c)

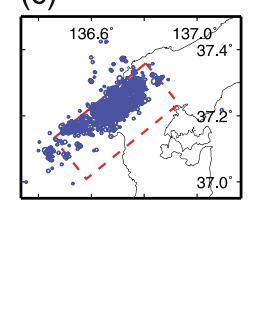

Fig. 6. (a) Estimated slip distribution on a rectangular fault plane. Colors correspond to the amount of slip and arrows indicate the slip directions. (b) Aftershock hypocenters projected on the fault plane. Red star denotes the hypocenter of the main shock. (c) Fault location in plane view (red box), plotted with aftershock epicenters.

Table 3. Optimum fault parameters for a slip distribution model.

\begin{tabular}{ccccc}
\hline Strike angle & Dip angle & Maximum slip & Rake angle $^{\mathrm{a}}$ & $M_{\mathrm{w}}{ }^{\mathrm{b}}$ \\
\hline $\mathrm{N} 50.7^{\circ} \mathrm{E}$ & $48^{\circ}$ & $1.4 \mathrm{~m}$ & $115^{\circ} \mathrm{N}$ & 6.63 \\
\hline
\end{tabular}

${ }^{\text {a }}$ That of the maximum slip patch. ${ }^{b}$ Rigidity $3.0 \times 10^{10} \mathrm{~N} / \mathrm{m}^{2}$ assumed.

ever, as discussed above, the shallow slip is not an artifact considering that a deeper top margin leads to a worse data fit (Fig. 4(b)). The aftershocks seem to have occurred on and around the dominant slip area (Fig. 6(b)). For further discussion on the relationships between the coseismic slip and the aftershock distribution, a more extensive examination is required. Parameters of our final preferred model are listed in Table 3.

\section{Conclusions}

An ascending and a descending interferograms for mapping the coseismic displacements of the 2007 Noto Hanto earthquake were computed using PALSAR data. The interferograms are highly coherent and clearly show up to about 50 and $20 \mathrm{~cm}$ of ground displacements in the line-of-sight directions corresponding to the ascending and descending orbits, respectively. There is no sign of phase discontinuities associated with a surface fault movement, indicating that the fault did not reach the ground, at least not on the land area.

The preferred fault model determined from the aftershock hypocenter locations, InSAR data, and GEONET GPS data has a dip angle of $48^{\circ}$ and a strike angle of $\mathrm{N} 50.7^{\circ} \mathrm{E}$. The dip angle is not well constrained in the tested range of $40^{\circ}$ to $60^{\circ}$. Dominant slip areas are lo- 
cated at depths between 4 and $10 \mathrm{~km}$ above the mainshock hypocenter and its upper extension to the seafloor in the western area. Many aftershocks seem to have occurred on and around the area of dominant slip.

Acknowledgments. The authors are grateful to the two anonymous reviewers whose comments improved the quality of the paper. PALSAR data used in this study are shared by PIXEL (PALSAR Interferometry Consortium to Study our Evolving Land surface) and are provided from JAXA through a joint research contract between JAXA and the Earthquake Research Institute, University of Tokyo. The ownership of PALSAR data belongs to JAXA and Ministry of Economy, Trade and Industry. This research is conducted as a joint research project of the Earthquake Research Institute, University of Tokyo. We are grateful for the earthquake catalog data provided by the Japan Meteorological Agency and the GEONET GPS data provided by the GSI.

\section{References}

Akaike, H., Likelihood and Bayes procedure, in Baysian Statistics, edited by J. M. Bernardo et al., 143-166, Univ. Press, Valencia, Spain, 1980.

Geographical Survey Institute, On the crustal deformations associated with the 2007 Noto Peninsula earthquake, http://cais.gsi.go.jp/ HENDOU/index27.html, 2007.

Hanssen, R. F., Radar Interferometry-Data Interpretation and Error Analysis, Kluwer Academic Publishers, 2001.

Hashimoto, M., H. Takahashi, R. Doke, M. Kasahara, A. Takeuchi, K. Onoue, Y. Hoso, Y. Fukushima, K. Nakamura, F. Ohya, R. Honda, M. Ichiyanagi, T. Yamaguchi, T. Maeda, and Y. Hiramatsu, Postseismic displacements following the 2007 Noto peninsula earthquake detected by dense GPS observation, Earth Planets Space, 60, this issue, 139-144, 2008.

Ishiwatari, A., Y. Hiramatsu, K. Koizumi, H. Tsuchihashi, and Y. Kono, Fault outcrops and tombstone fall-down rates of the 2007 Noto-hanto Earthquake, central Japan, Japan Geoscience Union Meeting, Z255P027, 2007.

Ito, K., H. Wada, K. Watanabe, H. Horikawa, T. Tsukuda, and K. Sakai, 1993 off Noto Peninsula earthquake, Annuals. Disas. Prev. Res. Inst., Kyoto Univ., 37, 325-341, 1994 (in Japanese).

Menke, W., Geophysical Data Analysis: Discrete Inverse Theory, revised edition, Academic Press, Inc., 1989.

NASA Landsat Program, Landsat ETM+ scene L7CPF20000401 20000630_08, USGS, Sioux Falls, 6/15/2000, 2004.

Okada, Y., Surface deformation due to shear and tensile faults in a halfspace, Bull. Seismol. Soc. Am., 75, 1135-1154, 1985.

Rosen, P. A., S. Hensley, H. A. Zebker, F. H. Webb, and E. J. Fielding, Surface deformation and coherence measurements of Kilauea Volcano, Hawaii, from SIR C radar interferometry, J. Geophys. Res., 101(E10), 23,109-23,126, 1996.

Sambridge, M., Geophysical inversion with a neighbourhood algorithmI. Searching a parameter space, Geophys. J. Int., 138, 479-494, 1999.

Samet, H. and R. E. Webber, Hierarchical data structures and algorithms for computer graphics. I. Fundamentals, IEEE Comput. Graphics Appl., 8(3), 48-68, 1988.

Tsukuda, T., H. Wada, K. Sakai, and K. Ito, Aftershock distribution of the 1993 M6.6 earthquake off Noto peninsula and its relation to tectonic features, Bull. Earthquake Res. Inst. Univ. Tokyo, 69, 1-18, 1994.

Y. Fukushima (e-mail: yofukushima@rcep.dpri.kyoto-u.ac.jp), T. Ozawa, and M. Hashimoto 